\title{
Survey of back and neck pain in South African ophthalmologists
}

\begin{tabular}{|c|c|}
\hline $\begin{array}{l}\text { Authors: } \\
\text { Craig D. Ande } \\
\text { Aubrey Makg } \\
\text { Karen Koetsie } \\
\text { André Rose }^{3}\end{array}$ & $\begin{array}{l}\operatorname{son}^{1} \oplus \\
\operatorname{tloe}^{1} \text { (1) } \\
\text { (1) }\end{array}$ \\
\hline $\begin{array}{l}\text { Affiliations: } \\
\text { 'Division of O } \\
\text { Department } 0 \\
\text { Neuroscience } \\
\text { Health Scienc } \\
\text { of the Witwat } \\
\text { Johannesburg }\end{array}$ & $\begin{array}{l}\text { hthalmology, } \\
\text { f } \\
\text {, Faculty of } \\
\text { es, University } \\
\text { ersrand, } \\
\text { South Africa }\end{array}$ \\
\hline $\begin{array}{l}\text { 2Department } \\
\text { Ophthalmolog } \\
\text { Hospital NHS } \\
\text { Trust, Yeovil, L }\end{array}$ & $\begin{array}{l}\text { y, Yeovil } \\
\text { Inited Kingdom }\end{array}$ \\
\hline $\begin{array}{l}{ }^{3} \text { Centre for } \mathrm{He} \\
\text { Research \& D } \\
\text { University of } t \\
\text { Bloemfontein }\end{array}$ & $\begin{array}{l}\text { alth Systems } \\
\text { evelopment, } \\
\text { he Free State, } \\
\text { South Africa }\end{array}$ \\
\hline $\begin{array}{l}\text { Correspondin } \\
\text { Craig Anderso } \\
\text { craigbyte@gn }\end{array}$ & $\begin{array}{l}\text { g author: } \\
\text { n, } \\
\text { lail.com }\end{array}$ \\
\hline $\begin{array}{l}\text { Dates: } \\
\text { Received: } 245 \\
\text { Accepted: } 08 \\
\text { Published: } 04\end{array}$ & $\begin{array}{l}\text { ept. } 2020 \\
\text { Fec. } 2020 \\
\text { Feb. } 2021\end{array}$ \\
\hline $\begin{array}{l}\text { How to cite th } \\
\text { Anderson CD, } \\
\text { Koetsie K, Ros } \\
\text { back and neck } \\
\text { African ophth } \\
\text { Afr Vision Eye } \\
\text { 80(1), a616. h } \\
\text { 10.4102/aveh }\end{array}$ & $\begin{array}{l}\text { is article: } \\
\text { Makgotloe A, } \\
\text { A. Survey of } \\
\text { pain in South } \\
\text { Imologists. } \\
\text { Health. 2021; } \\
\text { tps://doi.org/ } \\
\text { v80i1.616 }\end{array}$ \\
\hline $\begin{array}{l}\text { Copyright: } \\
\text { (c) 2021. The } \\
\text { Licensee: AOS } \\
\text { is licensed un } \\
\text { Creative Comr } \\
\text { Attribution Lic }\end{array}$ & $\begin{array}{l}\text { uthor(s). } \\
\text { S. This work } \\
\text { ler the } \\
\text { nons } \\
\text { ense. }\end{array}$ \\
\hline Read online: & \\
\hline 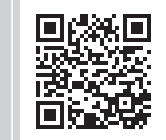 & $\begin{array}{l}\text { Scan this QR } \\
\text { code with your } \\
\text { smart phone or } \\
\text { mobile device } \\
\text { to read online. }\end{array}$ \\
\hline
\end{tabular}

Background: Back and neck pain are common in the general population and a common occupational condition. Occupationally related back and neck pain is common amongst ophthalmologists.

Aim: The aim of this study was to determine the prevalence of back and neck pain amongst South African ophthalmologists.

Setting: This was a survey that was conducted amongst South African ophthalmologists $(n=324)$ and ophthalmologists-in-training $(n=115)$.

Methods: The response rate was $44.8 \%(n=197)$. There was no sampling and a hyperlink to an electronic questionnaire, hosted on the REDCap survey platform, was sent to 440 potential respondents. A descriptive analysis was carried out using STATA version 15. Ethical approval was obtained from the University of Witwatersrand.

Results: Mean age was 47.1 years (standard deviation [s.d.] \pm 12.1$)$ and $62(31.5 \%)$ women. The cohort was stratified into specialists $(n=81,41.1 \%)$, subspecialists $(n=75,38.1 \%)$ and ophthalmologists-in-training $(n=41,20.8 \%)$. Most of the participants $(n=156,79.2 \%)$ were qualified ophthalmologists. Respondents reported current back pain ( $n=124,62.9 \%)$, lower back pain $(n=66,33.5 \%)$ and neck pain $(n=76,38.6 \%)$. The overall median pain rating (on a scale from 1 to 10$)$ was 4 . Respondents reported mild pain $(n=71,36 \%)$ and severe pain $(n=35,17.7 \%)$. Operating and using a slit lamp were pain aggravating factors in $36 \%(n=71)$ and $37.1 \%(n=73)$, respectively.

Conclusion: Back and neck pain are prevalent amongst South African ophthalmologists and comparable to other ophthalmologists worldwide.

Keywords: age; gender; height; job capacity; subspecialty; hours spent working; and specific questions about back and neck pain.

\section{Introduction}

Back and neck pain is widespread in our society today. ${ }^{1,2}$ The global prevalence of low back pain is estimated to be $38.9 \% .^{2}$ The global prevalence of neck pain is much more varied because of the large variability within the studies which assess this factor. It is estimated to range between $0.4 \%$ and $86.8 \% .{ }^{1}$ This high prevalence rate is also true amongst surgeons. ${ }^{3}$ In the United States, $86.9 \%$ of laparoscopic surgeons report physical discomfort as a result of their work. ${ }^{4}$ In their systematic review that investigated the prevalence of work-related musculoskeletal disorders amongst surgeons and interventionalists $(n=2815)$, Epstein et al. (2017) found that the 12-months prevalence estimate of back and neck pain was $49 \%$ and $60 \%$, respectively. ${ }^{3}$ Globally the prevalence of back and neck pain in ophthalmologists ranges between $26 \%-82 \%$ and $18 \%-93 \%$, respectively. $5,6,7,8,9,10,11,12,13,14$

Ophthalmology is a physically and mentally demanding speciality. Kitzmann et al. compared family physicians and eye care physicians and found that more eye care physicians classified themselves into a high strain job category and had more job factors associated with musculoskeletal symptoms than family physicians. ${ }^{10}$ Approximately half of ophthalmic plastic surgeons in a US-based survey agreed that specific components of their job could shorten their career length, interfere with their quality of life or lead to spinal disorders. ${ }^{12}$ High patient loads and high volumes of surgery have been shown to contribute to the development of these symptoms. ${ }^{8,9}$ In a survey study of Saudi Arabian eye care professionals, musculoskeletal symptoms were reduced during vacation periods, thus suggesting a relationship with occupation. ${ }^{14}$ Ergonomics in ophthalmology are less than ideal. Shaw et al. investigated the mechanical exposure of vitreoretinal 
surgeons and found that these ophthalmologists were often exposed to postures that are more demanding than neutral positions. ${ }^{15}$ Despite the ergonomic risks of the profession, many ophthalmologists are not aware of this problem. Of the ophthalmologists surveyed in India by Kaup et al., 27.9\% ( $n=105 / 377)$ had informed themselves on ergonomics and only $2.4 \%$ had used an ergonomist in their practice. ${ }^{6}$ In this study, there was a significant association between 'lack of good clinic and operation room ergonomic practices' and musculoskeletal symptoms. ${ }^{6}$

Musculoskeletal disorders may affect service delivery, and Dhimitri et al. found that $15 \%(n=697)$ of ophthalmologists in their survey reported some limitation in their work. ${ }^{8}$ In a survey of ophthalmic plastic surgeons $(n=130)$, it was found that $54(42 \%)$ surgeons had adjusted their operating practice, $10(8 \%)$ had undergone surgery, and $12(9 \%)$ had stopped operating as a result of spinal issues. ${ }^{12}$

Work-related musculoskeletal symptoms are widespread in ophthalmology, and the practice setting in which most ophthalmologists find themselves contributes to these problems. ${ }^{6,15}$ It has been recommended that improved ergonomics and education about these problems are important to reduce their impact. ${ }^{6,15}$ To the best of our knowledge back and neck pain in ophthalmologists has not been investigated in South Africa and this study aimed to address this knowledge gap. The aim of this study was to determine the prevalence of back and neck pain in South African ophthalmologists and associated aggravating factors.

\section{Methods}

\section{Study population and data collection}

This was a survey using an electronic questionnaire amongst South African based board-certified ophthalmologists and ophthalmologists-in-training. The study was based in South Africa. According to Resnikoff et al. and the International Council of Ophthalmology there are 324 registered ophthalmologists in the country. ${ }^{16}$ There are approximately 115 ophthalmologists-in-training in South Africa (this is an estimate from the Ophthalmological Society of South Africa, 2018). The ophthalmologists-in-training consisted of medical officers (pre-residents) and registrars (residents). The registrar (residency) programme is a four-year training programme. In South Africa, these are considered junior doctors. There was no sampling and all eligible doctors were invited to participate in the study. The questionnaire collected information on age, gender, height, job capacity, subspecialty, hours spent working and specific questions about back and neck pain. The questionnaire was administered on the REDCap platform, which is hosted by the University of Witwatersrand. This is a secure, web-based software platform designed for studies comprising of several research tools. ${ }^{17,18}$ The data were imported directly from this platform. The questionnaire was emailed to the participants who completed it anonymously. Informed consent was provided and participation was voluntary. Data were collected from
January to May 2019. Of the approximately 439 people invited, the cohort consisted of 197 people who completed the questionnaire giving a response rate of $44.8 \%$.

\section{Data analysis}

A descriptive analysis was done using STATA version 15 (StataCorp, College Station, United States [US]). Frequencies were calculated for categorical data, mean and standard deviations (s.d.) were calculated for parametric data, medians and interquartile ranges (IQRs) were computed for non-parametric data. Odds ratios (ORs) with 95\% confidence intervals (CIs) were calculated for risk factors related to back pain. A multivariate logistic analysis using a stepwise backward approach was performed to test the simultaneous association between back pain and different variables.

\section{Ethical consideration}

Ethics approval for the study was granted by the Human Research Ethics Committee (Medical) of the University of the Witwatersrand. (Certificate number: M180737).

\section{Results}

The age was normally distributed, and the mean age was 47.1 years (s.d. \pm 12.1 ). The minimum age was 27 and the maximum age was 78 . The age was categorised into two groups, $<47$ years and $\geq 47$ years, based on the mean age. There were $62(31.5 \%)$ women and $135(68.5 \%)$ men in the cohort.

The cohort was stratified into specialists $(n=81,41.1 \%)$, subspecialists $(n=75,38.1 \%)$ and junior doctors $(n=41$, $20.8 \%)$. The majority of the participants $(n=156,79.2 \%)$ were qualified ophthalmologists.

Figure 1 illustrates the proportion of self-reported areas of expertise of the 75 subspecialists. There were 19 (25.5\%) specialists who indicated they worked in a subspecialty but had not indicated the specific speciality. In this category, we

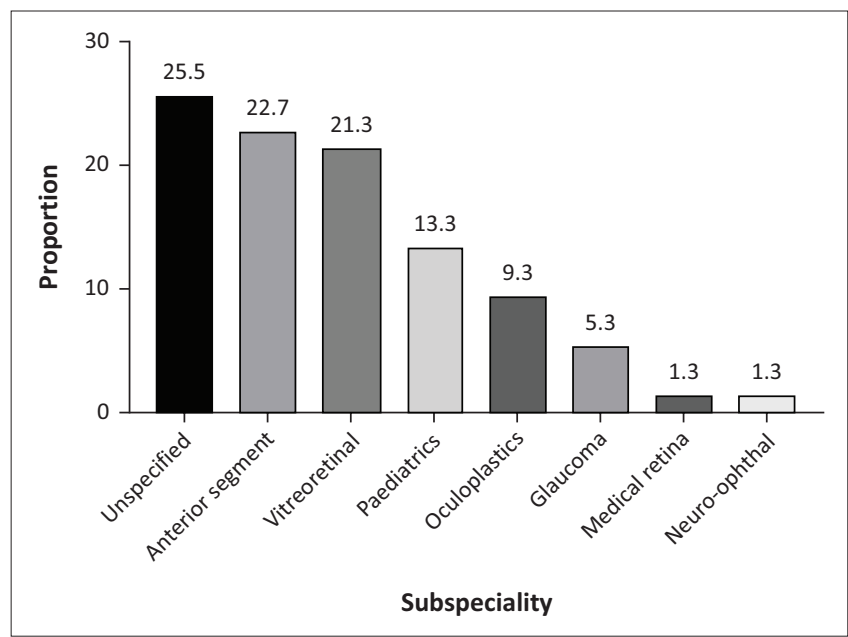

FIGURE 1: The proportion of 75 subspecialists working in the various subcategories of ophthalmological specialties. 
included participants who indicated they worked in more than one speciality.

The participants worked in the state sector $(n=68,34.5 \%)$, private sector $(n=108,54.8 \%)$ and a combination of state and the private sectors $(n=21,10.7 \%)$. Table 1 describes the characteristics of the different strata and their occupational history. Participants self-reported the number of hours they worked per week in a clinic setting or performing surgery.

There were variable responses regarding reporting pain, how they subjectively quantified it and how they managed the pain. Participants were asked to report the pain in the previous month, the previous three months or in the previous year. They reported the factors that aggravated the pain. The pain was managed using either physiotherapy, medication, surgery and exercise or a combination of these modalities. From the cohort, the respondents who reported to be currently suffering from musculoskeletal back pain was $62.9 \%(n=124)$. Lower back pain was reported by $33.5 \%$ of respondents $(n=66)$ and neck pain was reported by $38.6 \%(n=76)$. The overall median pain rating (on a scale from 1 to 10 ) was 4 . Most pain that was reported was mild, $43.2 \%(n=85)$, but severe pain was reported by $17.7 \%$ $(n=35)$. Operating and slit lamp utilisation were found to be aggravating factors for pain in $36 \%(n=71)$ and $37.1 \%$ $(n=73)$, respectively. Table 2 describes the back and neck pain experienced by the doctors working in ophthalmology, pain characterisation, aggravating and relieving factors and treatment modalities.

Odds ratios were calculated for the association between various risk factors currently reporting muscular skeletal pain. These included age, sex, height, rank, trauma history, time spent working overall, time spent in the clinic weekly and time spent operating. None of these associations were found to be statistically significant. Table 3 describes these ORs.

A logistic regression model using a backward regression approach was used to assess covariates that predict for musculoskeletal pain. The following variables were assessed: age, sex, height, rank, time spent working overall, time spent in the clinic weekly and time spent operating. None of these associations were found to be statistically significant. Table 4 describes the covariates that predict for muscular skeletal pain.

TABLE 1: Demographics and occupational history of 197 doctors working in ophthalmology.

\begin{tabular}{|c|c|c|c|c|c|c|c|c|}
\hline \multirow[t]{2}{*}{ Covariate } & \multicolumn{2}{|c|}{ Specialist $n=81(41.1 \%)$} & \multicolumn{2}{|c|}{ Subspecialist $n=75(38.1 \%)$} & \multicolumn{2}{|c|}{ Junior $n=41(20.8 \%)$} & \multicolumn{2}{|c|}{ Total $N=197(100.0 \%)$} \\
\hline & $n$ & $\%$ & $n$ & $\%$ & $n$ & $\%$ & $n$ & $\%$ \\
\hline \multicolumn{9}{|l|}{ Age in years } \\
\hline Mean & 49.9 & - & 51.6 & - & 33.0 & - & 47.1 & - \\
\hline s.d. & 11.0 & - & 10.3 & - & 3.6 & - & 12.1 & - \\
\hline Minimum & 31 & - & 34 & - & 27 & - & 27 & - \\
\hline Maximum & 71 & - & 78 & - & 45 & - & 78 & - \\
\hline \multicolumn{9}{|l|}{ Sex } \\
\hline Male & 63 & 77.8 & 56 & 74.7 & 16 & 39.1 & 135 & 68.5 \\
\hline Female & 18 & 22.2 & 19 & 25.3 & 25 & 60.9 & 62 & 31.5 \\
\hline \multicolumn{9}{|l|}{ Height (cm) } \\
\hline Mean & 173 & - & 177 & - & 170 & - & 174 & - \\
\hline s.d. & 7.9 & - & 8.5 & - & 11.3 & - & 9.4 & - \\
\hline \multicolumn{9}{|l|}{ Work setting } \\
\hline State & 13 & 16.1 & 16 & 21.3 & 39 & 95.2 & 68 & 34.5 \\
\hline Private & 62 & 76.5 & 45 & 60.0 & 1 & 2.4 & 108 & 54.8 \\
\hline Both & 6 & 7.4 & 14 & 18.7 & 1 & 2.4 & 21 & 10.7 \\
\hline \multicolumn{9}{|l|}{ Hours worked } \\
\hline \multicolumn{9}{|c|}{$\begin{array}{l}\text { Overall hours } \\
\text { worked per week }\end{array}$} \\
\hline Median & 40 & - & 40 & - & 39 & - & 38 & - \\
\hline IQR & $32-42$ & - & $34-43$ & - & $30-42$ & - & $26.5-50$ & - \\
\hline$\geq 40 \mathrm{~h} /$ week & 71 & 87.7 & 59 & 78.7 & 30 & 73.2 & 160 & 81.2 \\
\hline$<40 \mathrm{~h} /$ week & 10 & 12.3 & 16 & 21.3 & 11 & 26.8 & 37 & 18.8 \\
\hline \multicolumn{9}{|c|}{$\begin{array}{l}\text { Hours worked in } \\
\text { clinic per week }\end{array}$} \\
\hline Median & 30 & - & 25 & - & 30 & - & 30 & - \\
\hline IQR & $24-35$ & - & $20-30$ & - & $20-32$ & - & $22-33$ & - \\
\hline$\geq 30 \mathrm{~h} /$ week & 53 & 65.4 & 29 & 38.7 & 22 & 53.7 & 104 & 52.8 \\
\hline$<30 \mathrm{~h} /$ week & 28 & 34.6 & 46 & 61.3 & 19 & 46.3 & 93 & 47.2 \\
\hline \multicolumn{9}{|c|}{$\begin{array}{l}\text { Hours operating } \\
\text { per week }\end{array}$} \\
\hline Median & 8 & - & 10 & - & 6 & - & 8 & - \\
\hline IQR & $6-10$ & - & $8-15$ & - & $3-8$ & - & $3-8$ & - \\
\hline$\geq 8 \mathrm{~h} /$ week & 54 & 66.7 & 57 & 76.0 & 17 & 41.5 & 120 & 64.9 \\
\hline
\end{tabular}

Note: Doctors were stratified into three categories: specialists (81), subspecialists (75) and junior doctors (41).

$I Q R$, interquartile range; s.d., standard deviation. 
TABLE 2: Muscular skeletal pain experienced by the 197 doctors working in ophthalmology, the characterisation of their pain and the factors that aggravated and relieved the pain and the modalities they used to manage their pain.

\begin{tabular}{|c|c|c|c|c|c|c|c|c|}
\hline \multirow[t]{2}{*}{ Covariate } & \multicolumn{2}{|c|}{ Specialist $n=81(41.0 \%)$} & \multicolumn{2}{|c|}{ Subspecialist $n=75(38.0 \%)$} & \multicolumn{2}{|c|}{ Junior $n=41(21.0 \%)$} & \multicolumn{2}{|c|}{ Total $N=197(100.0 \%)$} \\
\hline & $n$ & $\%$ & $n$ & $\%$ & $n$ & $\%$ & $n$ & $\%$ \\
\hline Current MS pain & 54 & 66.7 & 46 & 61.3 & 24 & 58.5 & 124 & 62.9 \\
\hline \multicolumn{9}{|l|}{ Location of pain $\dagger$} \\
\hline Lower back & 33 & 40.7 & 20 & 26.7 & 13 & 31.7 & 66 & 33.5 \\
\hline Mid back & 8 & 9.9 & 4 & 5.3 & 6 & 14.6 & 18 & 9.1 \\
\hline Upper back & 14 & 17.2 & 10 & 13.3 & 14 & 34.2 & 38 & 19.3 \\
\hline Neck & 28 & 34.5 & 37 & 49.3 & 11 & 26.8 & 76 & 38.6 \\
\hline \multicolumn{9}{|l|}{ Pain rating: } \\
\hline Median & 4 & - & 4 & - & 5 & - & 4 & - \\
\hline IQR & $3-5.5$ & - & $3-6$ & - & $3-6$ & - & $1-8$ & - \\
\hline \multicolumn{9}{|l|}{ Category of pain } \\
\hline No pain reported & 29 & 35.8 & 29 & 38.7 & 19 & 46.3 & 77 & 39.1 \\
\hline $\begin{array}{l}\text { Mild/moderate } \\
\text { pain }\end{array}$ & 39 & 48.1 & 33 & 44.0 & 13 & 31.7 & 85 & 43.2 \\
\hline Severe & 13 & 16.1 & 13 & 17.3 & 9 & 22.0 & 35 & 17.7 \\
\hline \multicolumn{9}{|l|}{$\begin{array}{l}\text { Duration of pain in } \\
\text { years }\end{array}$} \\
\hline Median & 6 & - & 6 & - & 5 & - & 6 & - \\
\hline IQR & $0-45$ & - & $0-34$ & - & $0-52$ & - & $0-40$ & - \\
\hline
\end{tabular}

\section{Subjective \\ experience of pain \\ reported by \\ participants§}

In previous month

Median number of

episodes reported

IQR

$0-45$

0-34

$0-52$

$0-40$

In previous 3

months

Median number of

episodes reported

IQR

In previous year

Median number of

episodes reported

IQR

$51-$

43

$-10$

49

\section{4}

2-10

42

20

$.5-11$

22

$\begin{array}{lll}9.5 & - & 13.5\end{array}$

6-30

$6-30$

6-20

40

30

23

30

12-76

$12-240$

114

4

2-10

113

12

6-30

110

30

12-100

12-76

Affects ADL

29

35.8

36

4

48.0

48.0
5.3

24

24
4

3-35

3.5

Median sick days

1-10

7

$\begin{array}{cc}32.1 & 34 \\ 17.3 & 5 \\ 45.7 & 23\end{array}$

5

23

$\begin{array}{cc}38.3 & 37 \\ 1.2 & 3 \\ 45.7 & 22 \\ 25.9 & 10 \\ 40.7 & 20 \\ 3.7 & 1 \\ 93.8 & 74 \\ 70.4 & 59 \\ 23.5 & 20 \\ 38.3 & 33\end{array}$

37

49.3

45.3

6.7

30.7

11
7
13

13

26.8

31.7

58.5

9.8

89

2-9

15

5

45.2

Pain management

Physiotherapy and

31

3

Surgery

Medication

1

Paracetamol

37

21

NSAID

33

Opiates

Exercise $\uparrow \dagger$

Cardiott

Weightstt

Stretchingt:

38.3

49.3
4.0
29.3
13.3
26.7
1.3
93.8
78.7
26.7
44.0

14

34.2

82

31.7

24.4

-

4.9

85.4

70.7

26.8

34.2

$\begin{array}{cc}34.2 & 82 \\ - & 4 \\ 31.7 & 72 \\ 24.4 & 4 \\ - & 64 \\ 4.9 & 6 \\ 85.4 & 185 \\ 70.7 & 145 \\ 26.8 & 5 \\ 34.2 & 78\end{array}$

$\begin{array}{ll}71 & 36.0 \\ 26 & 13.2 \\ 73 & 37.1\end{array}$

IQR, interquartile range; MS, musculoskeletal; ADL, activities of daily living; NSAID, nonsteroidal anti-inflammatory drug.

$\dagger$, Participants may have indicated multiple areas that were affected.

$\$$. Pain was scored on a scale of $1-10$.

$\S$, The calculation is based on the number of participants indicating that they had experienced pain in the specified time periods.

I, Participants may have indicated using more than one type of analgesia.

$\dagger$, Exercised for at least 1 hour per week.

$\$$, May have participated in more than one type of exercise. 
TABLE 3: Odds ratios and 95\% confidence intervals for the association between various risk factors currently reporting muscular skeletal pain.

\begin{tabular}{|c|c|c|c|c|}
\hline Covariate & OR & s.e. & $95 \% \mathrm{Cl}$ & $p$ \\
\hline \multicolumn{5}{|l|}{ Age (years) } \\
\hline$\leq 47$ & 0.726 & 0.215 & $0.406-1.298$ & 0.280 \\
\hline$>47$ & - & - & - & - \\
\hline \multicolumn{5}{|l|}{ Sex } \\
\hline Females & 1.876 & 0.627 & $0.975-3.611$ & 0.060 \\
\hline Males & - & - & - & - \\
\hline \multicolumn{5}{|l|}{$\begin{array}{l}\text { Height } \\
\text { (centimetres) }\end{array}$} \\
\hline$\leq 170$ & 1.065 & 0.315 & $0.596-1.903$ & 0.831 \\
\hline$>170$ & - & - & - & - \\
\hline \multicolumn{5}{|l|}{ Category } \\
\hline Specialists & 1.265 & 0.453 & $0.627-2.553$ & 0.512 \\
\hline Junior & - & - & - & - \\
\hline \multicolumn{5}{|l|}{ Trauma } \\
\hline No previous trauma & 0.753 & 0.312 & $0.334-1.696$ & 0.493 \\
\hline Previous trauma & - & - & - & - \\
\hline \multicolumn{5}{|l|}{$\begin{array}{l}\text { Time spent working } \\
\text { overall ( } \mathrm{h} / \text { week) }\end{array}$} \\
\hline$\leq 40$ & 0.834 & 0.311 & $0.401-1.732$ & 0.627 \\
\hline$>40$ & - & - & - & - \\
\hline \multicolumn{5}{|l|}{$\begin{array}{l}\text { Time spent in clinic } \\
\text { (h/week) }\end{array}$} \\
\hline$\leq 30$ & 0.954 & 0.281 & $0.535-1.702$ & 0.874 \\
\hline$>30$ & - & - & - & - \\
\hline \multicolumn{5}{|l|}{$\begin{array}{l}\text { Time spent } \\
\text { operating ( } h / \text { week) }\end{array}$} \\
\hline$\leq 8$ & 1.731 & 0.555 & $0.924-3.244$ & 0.087 \\
\hline$>8$ & - & - & - & - \\
\hline
\end{tabular}

Note: Standard error and $p$-values are reported as well.

$\mathrm{OR}$, odds ratios; s.e., standard error; $\mathrm{Cl}$, confidence intervals.

TABLE 4: Logistic regression model using a backward regression approach.

\begin{tabular}{lcccc}
\hline Covariate & OR & s.e. & $95 \% \mathbf{C l}$ & $p$ \\
\hline Age & 0.981 & 0.178 & $0.948-1.017$ & 0.311 \\
Sex & 2.058 & 1.054 & $0.754-5.617$ & 0.311 \\
Height & 1.012 & 0.022 & $0.969-1.057$ & 0.585 \\
Specialists & - & - & - & - \\
Subspecialist & 0.756 & 0.287 & $0.359-1.592$ & 0.287 \\
Junior doctor & 0.553 & 0.297 & $0.193-1.587$ & 0.462 \\
Hours per week & 0.521 & 0.185 & $0.260-1.045$ & 0.066 \\
Clinic hours per week & 1.015 & 0.185 & $0.260-1.045$ & 0.066 \\
$\begin{array}{l}\text { Operating hour per } \\
\text { week }\end{array}$ & 1.013 & 0.332 & $0.950-1.081$ & 0.684 \\
\hline
\end{tabular}

Note: Covariates that predict for muscular skeletal disorder in ophthalmologists.

$\mathrm{OR}$, odds ratios; s.e., standard error; $\mathrm{Cl}$, confidence intervals.

\section{Discussion}

This survey reported that $62.9 \%$ of the respondents suffered from back or neck pain. Compared with the global estimates of neck pain (mean 23.1\%) the cohort had a higher prevalence of $38.6 \%{ }^{1}$ The median pain score was 4 , suggesting that although common, the pain perceived by these doctors is not severe. However, despite this, $45.2 \%$ of the entire cohort report that these symptoms had an effect on their activities of daily living. The cohort was predominantly male (68.5\%), although, amongst the junior doctors the predominance was female $(60.9 \%)$. This may suggest a change in the gender proportions of the ophthalmic community in the younger cohort. Male predominance in ophthalmology is common worldwide. $7,8,9,11,13,19$
The prevalence of low back pain in this cohort (33.5\%) compares most similarly to Canadian ophthalmologists $(36 \%) .{ }^{11}$ Neck pain prevalence in this cohort compares most similarly to ophthalmologists in India in a study by Venkatesh et al.: $38.6 \%$ versus $33 \% .{ }^{9}$ The majority of these similar studies fell within a range of $26 \%-50.6 \% 5,6,7,8,9,10,11,12$ for reported back pain and $18 \%$ - 58\% for reported neck pain. $.5,6,7,9,9,10,11,12$ Studies done in Iran and Saudi Arabia fell outside of this range; reporting back and neck pain to range between $80 \%-82 \%$ and $69 \%-93 \%$, respectively. ${ }^{13,14}$ This comparison, therefore, suggests that South African ophthalmologists have comparable levels of reported neck and back pain to the rest of the world.

The median number of sick days taken was five days. Considering that the total number of working days per year is 260, these numbers are substantial. These self-reported symptoms have consequences beyond just the individual reporting them. From this cohort, four out of 197 respondents had surgery for musculoskeletal-related pain. Similarly, a United Kingdom-based study found that nine of 325 participating ophthalmologists required surgery for back pain. ${ }^{5}$ In a large systematic review of surgeons and interventionalists, $12 \%(n=277 / 2319)$ of the physicians with work-related musculoskeletal disorders required leave, modified their practice or retired early. ${ }^{3}$ A survey of Australian optometrists found 35 reports of hospitalisation and 91 reports of changing jobs or duties because of work-related musculoskeletal symptoms..$^{20}$ It is thus clear that these self-reported symptoms can have an impact on service delivery and has consequences for ophthalmologists and their long-term quality of life.

The ergonomics of ophthalmic practice are challenging. In this study, $36 \%$ of survey respondents reported operating as an aggravating factor for musculoskeletal symptoms and $37.1 \%$ and $13.2 \%$ said that slit-lamp utilisation and clinic work, respectively, aggravated their symptoms. The median number of hours worked in the clinic per week was 30, and the median number of hours spent operating per week was 8; this suggests that South African ophthalmologists are frequently exposed to these aggravating factors in their workplace. Shaw et al. showed that vitreoretinal surgeons using the indirect ophthalmoscope were exposed to postures that were ergonomically undesirable. ${ }^{15}$ Work-related factors performed by eye care physicians such as repetitive tasks and awkward positions have been identified and shown to be a risk factor for musculoskeletal symptoms. ${ }^{10,20}$ The association between poor ergonomic practices and musculoskeletal symptoms has been demonstrated in ophthalmologists. ${ }^{6} \mathrm{We}$ recommend that ophthalmologists would benefit from an ergonomic workplace assessment to mitigate developing musculoskeletal symptoms.

A strength of this research was as far as we could establish, that it was the first study in South Africa to look at neck and back pain in South African ophthalmologists and provided valuable insight into the topic in this group. Also, the response rate was good. The limitations of the study include that this was not a 
random sample and thus may not be representative of the study population. Also, despite the good response rate the study may have been underpowered and had there been more respondents there may have been more statistically significant associations as were demonstrated in other similar studies. There may have been selection bias as ophthalmologists with back or neck pain may have opted into the study and recall bias may have been introduced in self-reported questions. The survey was limited to questions on musculoskeletal disorders related to the spine and other causes for these symptoms may have been missed. Workplace ergonomic assessments were not carried out and we recommend that future studies objectively assess musculoskeletal disorders in the workplace of the ophthalmologist and relate findings to self-reported symptoms. This may assist to inform recommendations for workplace adjustments.

\section{Conclusion}

In conclusion, back and neck pain are common amongst South African ophthalmologists, and they compare similarly to their global counterparts. The impact that these symptoms may have on ophthalmologists can be significant as it may affect their daily life and clinical practice. Ophthalmic practice is ergonomically challenging, and it is recommended that improving this in the workplace may assist in lowering the burden of these musculoskeletal complaints.

\section{Acknowledgements}

The authors would like to acknowledge all the doctors who participated in our study. We appreciate their time and effort.

\section{Competing interests}

The authors have declared that no competing interests exist.

\section{Authors' contributions}

C.D.A. assisted in the study conception. C.D.A., A.M. and K.K. were involved in study design and data collection. A.R. participated in data analysis. C.D.A., A.M., K.K. and A.R. drafted and reviewed the article. All authors reviewed and approved the final manuscript.

\section{Funding information}

This research received no specific grant from any funding agency in the public, commercial or not-for-profit sectors.

\section{Data availability statement}

Data are available on reasonable request from the corresponding author.

\section{Disclaimer}

The views and opinions expressed in this article are those of the authors and do not necessarily reflect the official policy or position of any affiliated agency of the authors.

\section{References}

1. Hoy DG, Protani M, De R, Buchbinder R. The epidemiology of neck pain. Best Pract Res Clin Rheumatol. 2010;24(6):783-792. https://doi.org/10.1016/j.berh.2011. 01.019

2. Hoy D, Bain C, Williams $G$, et al. A systematic review of the global prevalence of low back pain. Arthritis Rheum. 2012;64(6):2028-2037. https://doi.org/10.1002/ art.34347

3. Epstein S, Sparer EH, Tran BN, et al. Prevalence of work-related musculoskeletal disorders among surgeons and interventionalists. JAMA Surg. 2018;153(2): e174947. https://doi.org/10.1001/jamasurg.2017.4947

4. Park A, Lee G, Seagull FJ, Meenaghan N, Dexter D. Patients benefit while surgeons suffer: An impending epidemic. J Am Coll Surg. 2010;210(3):306-313. https://doi. org/10.1016/j.jamcollsurg.2009.10.017

5. Chatterjee A, Ryan WG, Rosen ES. Back pain in ophthalmologists. Eye. 1994; 8(4):473-474. https://doi.org/10.1038/eye.1994.112

6. Kaup S, Shivalli S, Kulkarni U, Arunachalam C. Ergonomic practices and musculoskeletal disorders among ophthalmologists in India: An online appraisal. Eur J Ophthalmol. 2020;30(1):196-200. https://doi.org/10.1177/1120672 118815107

7. Hyer JN, Lee RM, Chowdhury HR, Smith HB, Dhital A, Khandwala M. National survey of back \& neck pain amongst consultant ophthalmologists in the United Kingdom. Int Ophthalmol. 2015;35(6):769-775. https://doi.org/10.1007/s10792 015-0036-z

8. Dhimitri KC, McGwin G, McNeal SF, et al. Symptoms of musculoskeletal disorders in ophthalmologists. Am J Ophthalmol. 2005;139(1):179-181. https://doi. org/10.1016/j.ajo.2004.06.091

9. Venkatesh R, Kumar S. Back pain in ophthalmology: National survey of Indian ophthalmologists. Indian J Ophthalmol. 2017;65(8):678-682. https://doi.org/ 10.4103/ijo.IJO_344_17

10. Kitzmann AS, Fethke NB, Baratz KH, Zimmerman MB, Hackbarth DJ, Gehrs KM A survey study of musculoskeletal disorders among eye care physicians compared with family medicine physicians. Ophthalmol. 2012;119(2):213-220. https://doi. org/10.1016/j.ophtha.2011.06.034

11. Diaconita V, Uhlman K, Mao A, Mather R. Survey of occupational musculoskeletal pain and injury in Canadian ophthalmology. Can J Ophthalmol. 2019;54(3):314-322. https://doi.org/10.1016/j.jcjo.2018.06.021

12. Sivak-Callcott JA, Diaz SR, Ducatman AM, Rosen CL, Nimbar AD, Sedgeman JA. A survey study of occupational pain and injury in ophthalmic plastic surgeons. Ophthalmic Plast Reconstr Surg. 2011;27(1):28-32. https://doi.org/10.1097/ IOP.0b013e3181e99cc8

13. Chams H, Mohammadi SF, Moayyeri A. Frequency and assortment of self-reported occupational complaints among Iranian ophthalmologists: A preliminary survey. Med Gen Med. 2004;6(4):1

14. Al-Marwani Al-Juhani M, Khandekar R, Al-Harby M, Al-Hassan A, Edward DP. Neck and upper back pain among eye care professionals. Occup Med. 2015; 65(9):754-757. https://doi.org/10.1093/occmed/kqv132

15. Shaw C, Bourkiza R, Wickham L, Mccarthy I, Mckechnie C. Mechanical exposure of ophthalmic surgeons: A quantitative ergonomic evaluation of indirect ophthalmoscopy and slit-lamp biomicroscopy. Can J Ophthalmol. 2017; 52(3):302-307. https://doi.org/10.1016/j.jcjo.2016.09.011

16. Resnikoff S, Felch W, Gauthier TM, Spivey B. The number of ophthalmologists in practice and training worldwide: A growing gap despite more than 200000 practitioners. Br J Ophthalmol. 2012;96(6):783-787. https://doi.org/10.1136/ bjophthalmol-2011-301378

17. Harris PA, Taylor R, Thielke R, Payne J, Gonzalez N, Conde JG. Research electronic data capture (REDCap) - A metadata-driven methodology and workflow process for providing translational research informatics support. J Biomed Inform. 2009;42(2):377-381. https://doi.org/10.1016/j.jbi.2008.08.010

18. Harris PA, Taylor R, Minor BL, et al. The REDCap consortium: Building an international community of software platform partners. J Biomed Inform 2019;95(December 2018):103208. https://doi.org/10.1016/j.jbi.2019.103208

19. McAlister C, Jin YP, Braga-Mele R, DesMarchais BF, Buys YM. Comparison of lifestyle and practice patterns between male and female Canadian ophthalmologists. Can J Ophthalmol. 2014;49(3):287-290. https://doi.org/ 10.1016/j.jcjo.2014.02.007

20. Long J, Naduvilath TJ, Hao L, et al. Risk factors for physical discomfort in Australian optometrists. Optom Vis Sci. 2011;88(2):317-326. https://doi.org/10.1097/OPX. Ob013e3182045a8e 